\title{
Condiciones óptimas de cultivo de linfocitos y análisis parcial del cariotipo de la tortuga cabezona, Caretta caretta (Testudines: Cheloniidae) en Santa Marta, Caribe Colombiano
}

\author{
Ellie Ann López ${ }^{1}$, Javier Hernández-Fernández ${ }^{2}$ \& Jaime Bernal-Villegas ${ }^{3}$ \\ Centro de Estudios en Biología Molecular, Gimnasio Campestre, Calle 165 No 19-50, Bogotá, Colombia. \\ 1. Universidad Federal de Paraná, Rua Konrad Kuno Frank 22, Curitiba, Brasil \\ 2. Genética, Biología Molecular \& Bioinformática, Universidad Jorge Tadeo Lozano, Cra. 4 No. 22-61, Bogotá, \\ Colombia; autor para correspondencia: javier.hernandez@utadeo.edu.co \\ 3. Pontificia Universidad Javeriana, Cra. 7 Calle 42 Bogotá, Colombia.
}

Recibido 23-IV-2007. Corregido 30-VI-2008. Aceptado 31-VII-2008.

\begin{abstract}
Lymphocyte culture and partial karyotype of the marine turtle Caretta caretta (Testudines: Cheloniidae) in Santa Marta, Colombian Caribbean. Over the past few years an important reduction in the number of nesting marine turtle Caretta caretta individuals has been registered in the Colombian Caribbean, raising the question of a possible extinction in the medium term. A conservation plan is needed. We studied the culture requirements for $C$. caretta lymphocytes and preliminary karyotype analysis for cytogenetic identification, immunological study and toxicology without the need to kill individuals. Peripheral blood samples were obtained from 47 individuals in Santa Marta, Colombia and tests were made until optimal conditions were established for lymphocyte culture. The karyotype had 56 chromosomes, 32 macrochromosomes and 24 microchromosomes. An ideogram showed that $C$. caretta has four groups of chromosomes. Sexual chromosomes were not observed. These results do not coincide with the karyotype described from the Pacific (Japan). The present study is the first to include a complete description of the chromosome morphology of turtles from the Atlantic Ocean. It is possible that one of the adaptive strategies of this species is genetic interchange with other species of the family, producing viable hybrids. Individuals in this study might be viable hybrids of $C$. caretta and further molecular studies are needed. Rev. Biol. Trop. 56 (3): 1459-1469. Epub 2008 September 30.
\end{abstract}

Key words: karyotype, chromosomes, ideogram, Caretta caretta, Atlantic Ocean.

Las tortugas marinas han sido catalogadas a nivel mundial como especies en peligro de extinción y en la actualidad son protegidas y conservadas, directa o indirectamente, mediante diversos convenios internacionales como el CITES, así como por Leyes y Decretos Nacionales (INVEMAR 2000, INVEMAR 2002). Uno de ellos es el Programa Nacional para la Conservación de las Tortugas Marinas y Continentales en Colombia, el cual tiene como visión "Lograr en el año 2022 la conservación y manejo sostenible de las especies de tortugas en Colombia". (PNCTMCC 2002).

A pesar de contar con estos instrumentos jurídicos, pocas son las acciones concretas que se han adelantado en Colombia para la protección y conservación de las tortugas marinas. Como consecuencia el estado del conocimiento sobre las tortugas marinas y sus hábitats es precario y desordenado (INVEMAR 2000, INVEMAR 2002).

Este marco referencial hace evidente la necesidad de implementar programas de conservación; por lo tanto, es de suma importancia identificar las poblaciones de tortugas marinas que se encuentren presentes dentro de un área determinada, ya que la falta de conocimiento sobre la estructura de dichas poblaciones incrementa las dificultades para el desarrollo y planes efectivos para su manejo. Para esto 
se han empleado técnicas como marcas pasivas, telemetría satelital y estudios genéticos (Bowen et al. 2000). Estos últimos permiten reconocer poblaciones de una forma rápida y segura, sin embargo, las técnicas moleculares que son empleadas tienen costos muy elevados, lo cual impide su aplicación de una forma generalizada. Se hace necesario entonces implementar técnicas genéticas de menor costo, como la citogenética, que sirven como una herramienta para generar información de línea base, y con ella, identificar poblaciones en áreas determinadas.

Dentro de la Familia Cheloniidae se encuentra la especie $C$. caretta, pero actualmente no se cuenta con ningún estudio de citogenética realizado específicamente en el Caribe colombiano; sin embargo, investigaciones encaminadas a caracterizar el cariotipo de la especie fueron realizadas en Japón, principalmente. Kamezaki (1989) expone que $C$. caretta presenta 56 cromosomas diploides: 32 macrocromosomas (12 metacéntricos, 2 submetacéntricos, 6 subtelocéntricos, 12 acrocéntricos) y 24 microcromosomas. Sus resultados coinciden con los obtenidos por Bickham (1981) y Bickham y Carr (1983) aunque estos no realizan una descripción detallada del cariotipo de la especie, ni presentan la procedencia de los individuos muestreados. Nakamura (1949) registró que las tortugas de esta especie (provenientes de Shirahama, península de Kii, Japón) presentaban 57 cromosomas en hembras y 58 en machos. Estos resultados contrastan con los obtenidos por este mismo autor en 1937, donde afirma que las hembras de la especie $C$. caretta de la misma localidad presentaban 51 cromosomas y los machos 52 cromosomas.

Las técnicas empleadas en los estudios citogenéticos de tortugas marinas expuestos por Bickham y Carr (1983), Medrano y colaboradores (1987), Kamezaki (1989, 1990), $\mathrm{y}$ en general los realizados en quelonios por Killebrew (1975), Bickham, (1975), Bickham y Baker (1976) y Bickham y colaboradores (1980), requieren la muerte de los neonatos o de los individuos a analizar, ya que la metodología implementada requiere la inoculación in vivo con soluciones de colchicina. Después del sacrificio se pueden obtener células de bazo, pulmón, riñón (Medrano et al. 1987) o de espina medular (Kamesaki 1989). Estas células son cultivadas y estimuladas para obtener metafases, que posteriormente permiten obtener el cariotipo.

Se hace evidente la necesidad de generar técnicas de citogenética no invasivas para reptiles. Las características cariológicas de una especie derivan del estudio de sus cromosomas, quienes portan la información genética y son la máxima manifestación del plegamiento del DNA (Darnell et al. 1988). En los últimos años se ha utilizado el cultivo de linfocitos extraídos de la sangre periférica para efectuar estudios de citogenética en diferentes animales. Actualmente, existen estudios en tortugas de agua dulce que utilizan un protocolo similar y permiten la estandarización de los requerimientos de cultivos in vitro y la obtención de suficientes metafases para realizar una caracterización completa del cariotipo de tortugas de agua dulce (Maecha 1998, Ortiz y Rodríguez 2003, Ulsh et al. 2001).

El presente estudio tuvo como objetivo determinar los requerimientos del cultivo de linfocitos de $C$. caretta para la obtención de metafases a partir de muestras de sangre periférica (identificación citogenética). Además generar información sobre las características cariológicas de la especie en Santa Marta, Colombia; y proveer las bases para futuras investigaciones en citogenética de tortugas cabezonas en otras áreas de anidación o hábitat de la especie, en las cuales se logre identificar poblaciones mediante la comparación de bandas cromosómicas características de cada región analizada.

\section{MATERIALES Y MÉTODOS}

Extracción de Sangre Periférica. Se recolectaron muestras de sangre periférica en 47 ejemplares de $C$. caretta pertenecientes al Acuario Mundo Marino de Santa Marta (Colombia), dos de ellos eran individuos juveniles de dos años y medio de edad, y las 45 restantes eran tortugas mantenidas en cautiverio 
desde las primeras horas de eclosión hasta que cumplieron un año de edad. Las muestras fueron extraídas de ejemplares que se encontraban en perfecto estado de salud, registraban los mayores pesos y no presentaban deformaciones morfológicas. Después de seleccionar los individuos a muestrear se siguió el protocolo propuesto por Dutton (1996). Posteriormente, se trasladaron las muestras al Laboratorio de Biología Molecular del Gimnasio Campestre en Bogotá, para realizar los montajes de cultivos celulares. Durante el desarrollo del estudio fue necesario realizar muestreos de sangre varias veces en tiempos distintos para la realización de los diferentes experimentos.

Cultivo de linfocitos de $C$. caretta. En este estudio se estableció un protocolo para el cultivo de linfocitos de la tortuga marina Caretta caretta basado en las condiciones descritas por Ortiz y Rodríguez (2003), quienes lograron estandarizar un protocolo para el análisis citogenético de la tortuga dulceacuícola Podocnemis vogli. Cada uno de los tratamientos realizados se evaluó microscópicamente observándose entre 15-20 láminas. Se observaron barridos verticales en láminas portaobjetos en un microscopio de luz Olympus C20 en 10, 40 y $100 X$.

Caracterización del conjunto cromosómico. Se procedió a identificar los cromosomas por medio de digitalización de las láminas empleando un microscopio Zeiss Axiolab HBO 50/ ${ }_{\mathrm{AC}}$ conectado a una cámara digital Canon GS Power Shot. Se midieron 20 metafases pertenecientes a 12 individuos diferentes a través del programa de edición de imágenes Adobe Photoshop 8.0., el cual permite una medición exacta de la imagen obtenida (cm, píxeles, pulgadas). Se realizaron los cálculos promedio mediante las fórmulas propuestas por Ortiz y Rodríguez (2003) para encontrar la medida de longitud de los brazos p y q, el índice centromérico y el índice de proporcionalidad de los brazos. Se tuvo en cuenta la relación de los brazos, la longitud relativa del cromosoma y la longitud relativa del brazo.

\section{RESULTADOS}

Extracción de Sangre Periférica. Se realizaron 18 muestreos entre los 47 individuos analizados obteniéndose suficiente muestra de sangre utilizada para determinar las condiciones óptimas del cultivo de linfocitos de C. caretta. Se observó que el $1 \%$ de las extracciones de sangre realizadas se infectaron posiblemente por mal manejo en la asepsia durante la extracción. En el 2\% de los muestreos se obtuvieron células con morfología degenerativa, es decir, con membranas celulares poco definidas y citoplasmas traslucidos, esto se puede explicar por un efecto tóxico que causa en las células el anticoagulante (heparina sódica) (Bolten 1993). La casi totalidad de las muestras (9597\%) obtenidas cumplieron con los requisitos de asepsia y calidad de las células para realizar los cultivos de linfocitos.

Cultivo de linfocitos de C. caretta. Se realizaron un total de 352 experimentos con el fin de evaluar doce variables necesarias para obtener metafases de $C$. caretta (resultado no presentado). En el Cuadro 1 se resume el protocolo establecido para la obtención de metafases de C. caretta a partir de cultivo in vitro de linfocitos obtenidos de sangre periférica, generando así una técnica no invasiva que permite el análisis citogenético de esta especie de tortugas marinas. Este protocolo es muy diferente a los publicados previamente para la caracterización citogenética de tortugas de agua dulce (Maecha 1998, Ortiz y Rodríguez 2003, Ulsh et al. 2001).

Cariotipo de $\boldsymbol{C}$. caretta. El cariotipo observado coincide con el descrito por Kamesaki (1989), en cuanto al número de cromosomas diploides para $C$. caretta: 56 cromosomas: 32 macrocromosomas y 24 microcromosomas (Fig. 1). En la publicación de Kamesaki se describe el cariotipo de C. caretta con 12 cromosomas metacéntricos, 2 submetacéntricos, 6 subtelocéntricos y 12 acrocéntricos. Sin embargo, en esta investigación se encontraron 16 metacéntricos, 8 submetacéntricos, 
CUADRO 1

Protocolo estandarizado para la obtención de metafases de C. caretta a partir de sangre periférica

TABLE 1

Standardized protocol of metaphases of Caretta caretta from peripheral blood

1. Recolectar entre 1 y $10 \mathrm{ml}$ de sangre de $C$. caretta

2. Centrifugar a $500 \mathrm{rpm}$ durante 1 minuto.

3. Retirar el sobrenadante y la primera capa de células rojas en condiciones de asepsia.

4. Verter el sobrenadante en un tubo de centrifuga estéril y centrifugar a $500 \mathrm{rpm}$ por 1 minuto.

5. Retirar el sobrenadante y la primera capa de células rojas.

6. Verter el sobrenadante en un tubo de centrifuga estéril y centrifugar a $500 \mathrm{rpm}$ por 1 minuto.

7. Retirar solo la capa de células blancas y el sobrenadante.

8. Verter el sobrenadante en un tubo de centrifuga estéril.

9. A $1 \mathrm{ml}$ del plasma agregar $1 \mathrm{ml}$ de Suero Fetal Bovino (SFB).

10. Agregar $0.5 \mathrm{ml}$ del plasma enriquecido a un frasco de cultivo con $4 \mathrm{ml}$ de Medio TC 199, $0.2 \mathrm{ml}$ de penicilina, 0.4 $\mathrm{ml}$ de Fitohemaglutinina $(100.000 \mu \mathrm{g} / \mathrm{ml})$ y $1 \mathrm{ml}$ de SFB.

11. Incubar durante 95.5 horas a $32^{\circ} \mathrm{C}$.

12. Agregar $0.2 \mathrm{ml}$ de colchicina $(50 \mu \mathrm{g} / \mathrm{ml})$ agitar suavemente e incubar a $32{ }^{\circ} \mathrm{C}$ durante 45 minutos.

13. Pasar el contenido a un tubo de centrifuga estéril y centrifugar a $1.500 \mathrm{rpm}$ durante 10 minutos.

14. Descartar el sobrenadante con una pipeta pasteur plástica teniendo cuidado con el botón de células blancas.

15. Soltar el botón celular con golpes suaves en las paredes del tubo y adicionar $10 \mathrm{ml}$ de $\mathrm{KCl}(0.05 \mathrm{M}$, mantenida a 32 ${ }^{\circ} \mathrm{C}$ ) e incubar durante 40 minutos.

16. Adicionar $1 \mathrm{ml}$ de Carnoy frío 6:1. Tapar el tubo y mezclar suavemente por inversión tres o cuatro veces. Esperar 5 minutos.

17. Centrifugar a $1.500 \mathrm{rpm}$ durante 10 minutos.

18. Retirar el sobrenadante y descartarlo.

19. Adicionar $5 \mathrm{ml}$ de Carnoy frío $3: 1$, resuspender con la pipeta para homogenizar durante 5 minutos y esperar 10 minutos a temperatura ambiente.

20. Centrifugar a $1.500 \mathrm{rpm}$ durante 10 minutos.

21. Retirar el sobrenadante y descartarlo.

22. Adicionar $5 \mathrm{ml}$ de Carnoy frío 3:1, resuspender con la pipeta para homogenizar durante 5 minutos y esperar 30 minutos a temperatura ambiente.

23. Centrifugar a $1.500 \mathrm{rpm}$ durante 10 minutos.

24. Retirar el sobrenadante y descartarlo.

25. Adicionar $5 \mathrm{ml}$ de Carnoy frío 3:1, resuspender con la pipeta para homogenizar durante 5 minutos y esperar 15 minutos a temperatura ambiente.

26. Retirar el sobrenadante y descartarlo.

27. Agregar $2 \mathrm{ml}$ de fijador y homogenizar con la pipeta.

28. Extender las láminas a una distancia de $2 \mathrm{~m}$.

29. Teñir con una solución de Giemsa preparada recientemente.

30. Observar al microscopio.

4 subtelocéntricos, 4 acrocéntricos (Fig. 1), resultado que no concuerda con la clasificación dada por Kamesaki (1989), para cada par de cromosomas. Posiblemente por la falta de herramientas tecnológicas para clasificar de una forma más eficiente los cromosomas, ya que el artículo de Kamesaki no especifica el criterio de clasificación que empleó ni que ayuda tecnológica utilizó.
Ideograma del conjunto cromosómico de $\boldsymbol{C}$. caretta. Se realizaron mediciones de los cromosomas para obtener el ideograma de $C$. caretta observándose un grupo A conformado por doce (12) pares de cromosomas de mayor tamaño (Fig. 2). Los pares 2, 4, 9, 10, 11, 12, 13 y 14 metacéntricos con relaciones de brazos entre 1.2 y 1.6 , índice centromérico entre 39 y 44.9. Los pares $1,5,6$ y 7 submetacéntricos 

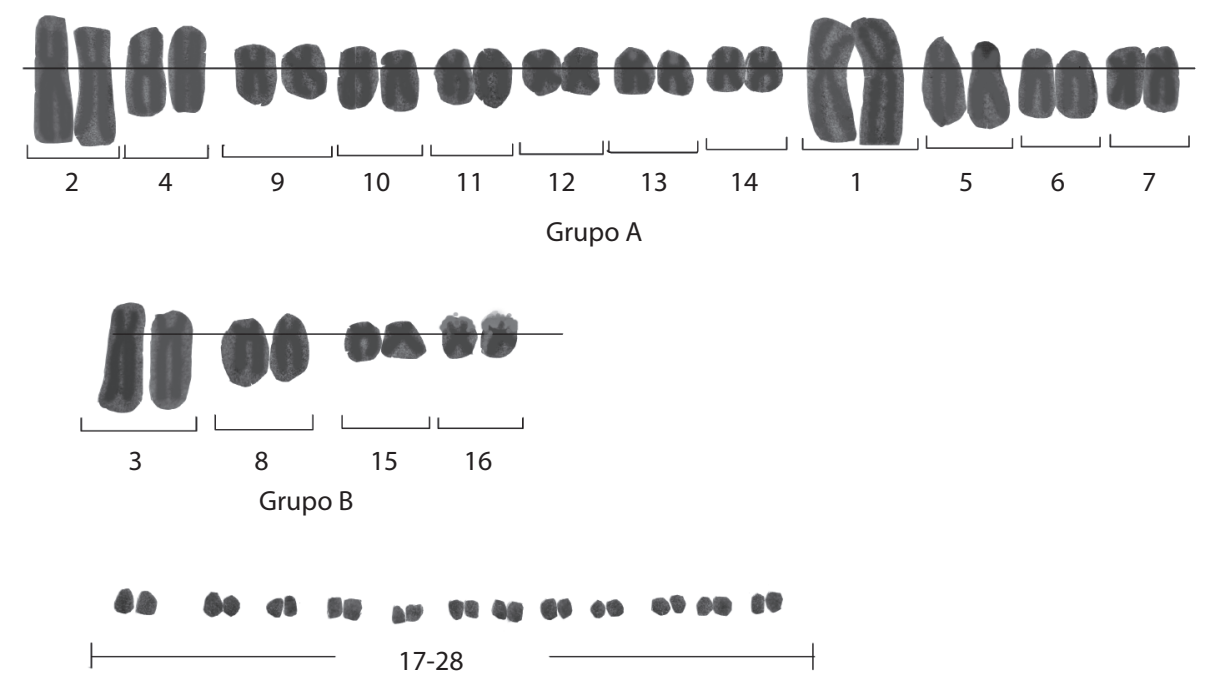

Grupo C

Fig. 1. Cariograma de Caretta caretta en coloración Giemsa que muestra la posición centromérica. Este cariotipo fue obtenido utilizando el protocolo estandarizado en este estudio (Tabla 1).

Fig. 1. Caretta caretta karyogram (Giemsa coloration) that shows the centromerical position. Cariotype was obtained using the standardized protocol from this study (Table 1).

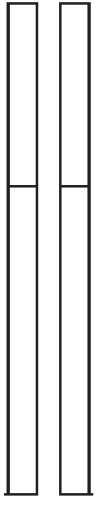

1

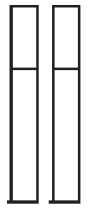

8

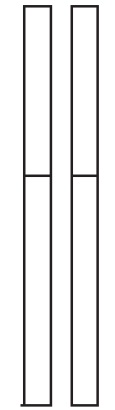

2

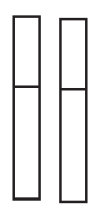

9

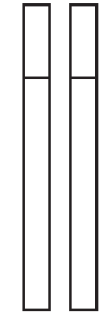

3

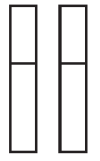

10

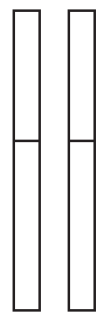

4

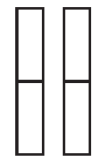

11

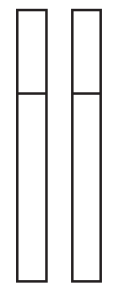

5

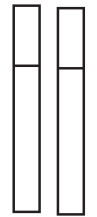

6

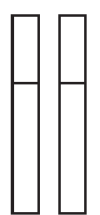

7

Fig. 2. Ideograma del complemento cromosómico de C. caretta.

Fig. 2. Chromosomal ideogram of the C. caretta complement. 
con una relación de brazos entre 1.7 y 2.3 y índice centromérico entre 29.9 y 37.3 (Fig. 2, Cuadro 2).

El Grupo B conformado por cromosomas medianos y pequeños, este grupo lo integran cuatro (4) pares de cromosomas (Fig 2, Cuadro 2). Los pares 3 y 8 subtelocéntricos con relaciones de brazos entre 1.8 y 2.1 , índice centromérico entre 23.3 y 24.1 . Los pares 15 y 16 acrocéntricos con relaciones de brazos de $1.3 \mathrm{y}$ 1.6, índice centromérico entre 12 y 12.5 (Fig. 2, Cuadro 2).

El Grupo C, conformado por los microcromosomas cuya posición centromérica es difícil de observar. Dentro de este grupo hay 12 pares de cromosomas. No se observaron cromosomas sexuales (Fig. 2, Cuadro 2).

\section{DISCUSIÓN}

El presente estudio es el primero realizado con tortugas marinas del Caribe colombiano que cuenta con la descripción completa de la morfología cromosómica para la especie Caretta caretta. Estos resultados están en desacuerdo con el cariotipo descrito por Kamesaki (1989) para la misma especie, que no le permitieron discernir con claridad la morfología del complemento mediante mediciones, al emplear la técnica directa de inoculación in vivo del inhibidor mitótico y sacrificio de los especímenes, que usualmente produce metafases muy condensadas si no se tiene adecuadamente estandarizado el protocolo (Ortiz et al. 2005). En el presente estudio mediante la técnica de cultivo de linfocitos, fue posible observar diferentes metafases en el mismo grado de condensación lo cual permite clasificar los cromosomas de una forma más clara. Adicionalmente, la utilización de herramientas tecnológicas que permiten el análisis de imágenes por computador evidencia una clasificación más precisa de los cromosomas. Mediante esta técnica y utilizando los índices generales de clasificación cromosómica formulados en el pasado (Bickham 1975, Bickham y Baker, 1976, Levan et al. 1964), en este estudio se logró representar por primera vez el ideograma de una tortuga marina. La implementación de esta técnica en estudios poblacionales para Caretta caretta o para otras especies de tortugas marinas que se encuentran en vía de extinción, permite el reconocimiento de su estructura cromosómica y la determinación de cambios entre poblaciones, realizar estudios de evolución cariológica y trabajos comparativos de bandas heterocromáticas y eucromáticas. La citogenética es esencial y su utilización se ha incrementado en el análisis de un amplio ámbito de fenómenos genéticos (Clark y Wall 1986). En este estudio se complementó el trabajo de Kamesaki (1989) al aportar una caracterización más detallada del cariotipo de la especie $C$. caretta, teniendo en cuenta el alto grado de amenaza de su extinción (UICN) y la necesidad de estudios a nivel genético que permitan caracterizar las poblaciones que son sometidas a explotación antrópica. Estudios futuros podrían permitir la realización de bandas cromosómicas, y con ellos, el análisis de los diferentes híbridos que se están produciendo naturalmente en el ambiente, asi como la evolución cariológica. Esto permitirá trazar planes de manejo de estas tortugas marinas.

Aunque esta no es una investigación de carácter poblacional se tuvieron en cuenta para el análisis algunos aspectos de la historia de vida de esta especie que han sido evidenciados por medio de estudios de genética molecular y que podrían relacionarse con los cambios cromosómicos observados en esta investigación con respecto a la descripción cariológica dada por Kamesaki (1989) para C. caretta. En los últimos años se han registrado un alto número de presiones sobre especies de tortugas marinas, sin embargo, no se ha detectado hasta qué nivel la modificación de hábitats ocasionada por acción antrópica, podría verse reflejado en algún tipo de adaptación de la especie a los cambios que vienen presentando los diferentes ecosistemas donde habitan. Bickham (1981), analizó la evolución cariotípica en quelonios y concluyó que estas especies presentan una tasa evolutiva de cariotipo desacelerada, principalmente en la Familia Cheloniidae, ya que no se han presentado reorganizaciones cromosómicas en esta familia; este autor también 


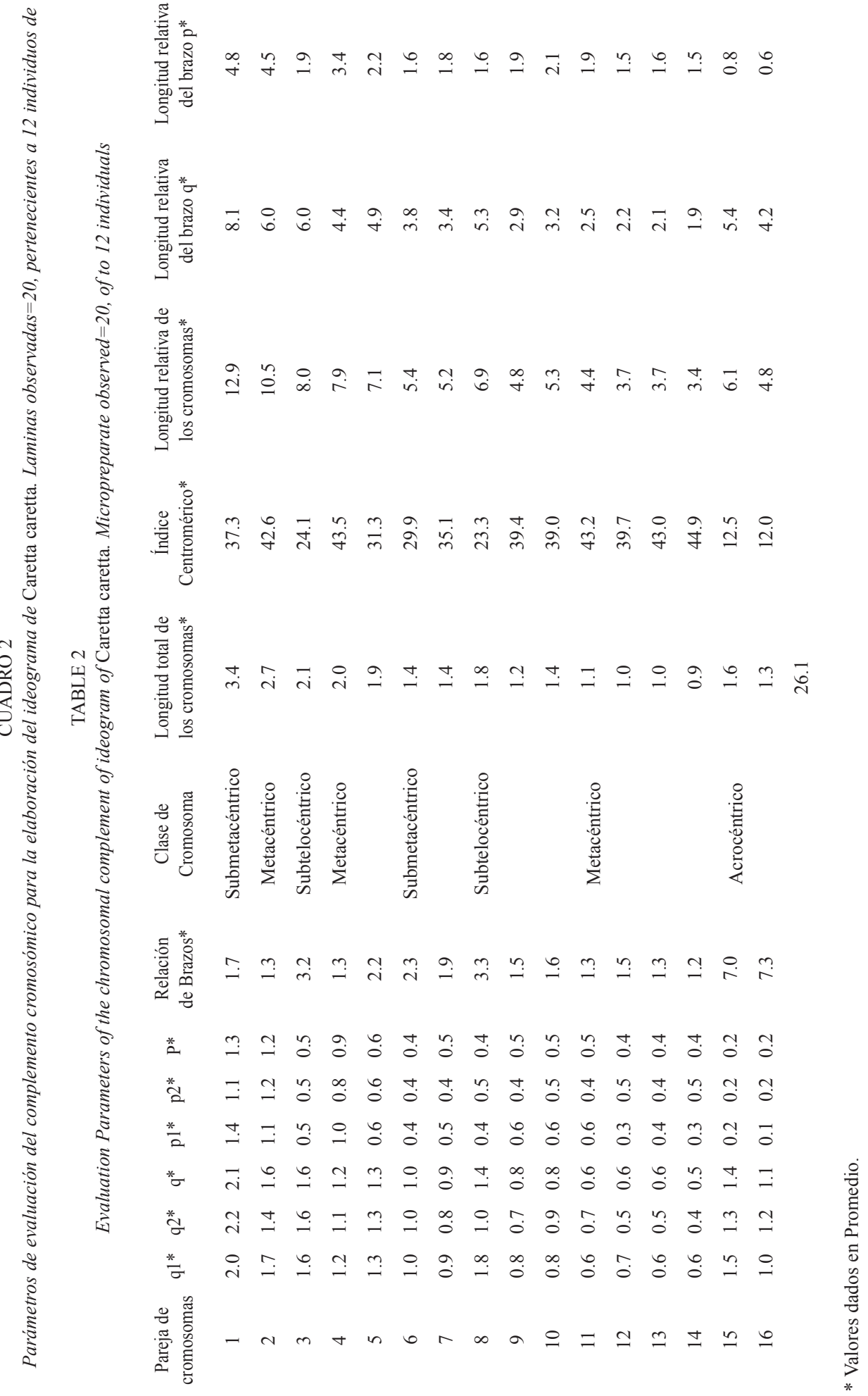


relaciona la evolución cariotípica con las estrategias de reproducción, vagilidad y tallas de la población. En consecuencia, la disminución en la tasa de evolución tanto morfológica como cromosómica es un patrón que sugiere un estancamiento evolutivo, al conseguir un máximo grado de adaptación, evidenciado por la inexistencia de variación a nivel cariológico dentro de las especies (Bickham y Carr, 1983). Sin embargo, Ortiz y colaboradores (2005) estudiando el cariotipo de Podocnemis vogli en solo 7 ejemplares, encontraron variaciones cromosómicas a nivel heterocromático, sugiriendo que esta especie es portadora de un nivel de variación genética y de polimorfismos intraespecíficos significativos, evidencia contraria al argumento presentado arriba. Estos resultados sugieren un modelo de diferenciación genética asociado a la distribución geográfica. Por lo tanto, las diferentes intervenciones que afectan a estas especies, como son, la depredación de los huevos, el consumo de tortugas adultas o juveniles y la acumulación de desechos orgánicos e inorgánicos en las playas de anidación, que ocasionan una reducción en la población y cambios en los hábitats que colonizan estas especies, deberían ser estudiados y analizados rigurosamente para ver las repercusiones que tienen sobre la adaptación y la evolución cariológica de esta especie. De esta forma la estandarización de técnicas para la obtención de cromosomas sin tener que sacrificar a los especímenes es de alta importancia.

Las diferencias en la descripción cariológica de Caretta caretta realizada en este estudio comparada con la de Kamesaki (1989) puede ser analizada teniendo en cuenta el origen de las muestras, ya que en las tortugas utilizadas por Kamesaki fueron colectadas en el Pacifico (Japón) y este estudio se realizó con muestras de sangre colectadas en el Caribe colombiano. La localidad de origen de las muestras es importante, si se tiene en cuenta que anteriormente han sido descritas dos subespecies de

CUADRO 3

Híbridos naturales producidos entre diferentes especies de tortugas marinas (Familia Cheloniidae)

TABLE 3

Naturals hybrids among sea turtles (Cheloniidae)

\begin{tabular}{|c|c|c|c|}
\hline Especies Progenitoras & Localidad de Origen & Análisis del hibrido & Referencias \\
\hline $\begin{array}{l}\text { Eretmochelys imbricata y } \\
\text { Caretta caretta }\end{array}$ & Islas Caimán & Morfología & Lewis, 1940 \\
\hline $\begin{array}{l}\text { Chelonia mydas y } \\
\text { Eretmochelys imbricata }\end{array}$ & Islas Caimán & & Hendrickson, 1980 \\
\hline \multirow{3}{*}{$\begin{array}{l}\text { Caretta caretta y } \\
\text { Eretmochelys imbricata }\end{array}$} & Península de Chita Japón & & Kamesaki, 1983 \\
\hline & Brasil & $\begin{array}{l}\text { Híbridos de segunda generación } \\
\text { (Análisis electroforético y de } \\
\text { proteínas) }\end{array}$ & $\begin{array}{l}\text { Concençião et al., } 1990 \\
\text { Marcovaldi et al. ,1997 }\end{array}$ \\
\hline & Florida, Estados Unidos & $\begin{array}{l}\text { Híbridos primera generación } \\
\text { (DNA nuclear y DNA } \\
\text { mitocondrial) }\end{array}$ & $\begin{array}{l}\text { Bowen, } 1996 \\
\text { Bowen y Karl, } 1997\end{array}$ \\
\hline $\begin{array}{l}\text { Caretta caretta y } \\
\text { Lepidochelys kempii }\end{array}$ & $\begin{array}{l}\text { Bahía de Chesapeake, } \\
\text { Estados Unidos }\end{array}$ & & Kar,1 1996 \\
\hline $\begin{array}{l}\text { Caretta caretta y } \\
\text { Chelonia mydas }\end{array}$ & $\begin{array}{l}\text { Australia } \\
\text { Japón }\end{array}$ & Morfología & Limpus pers. com. \\
\hline $\begin{array}{l}\text { Chelonia mydas y } \\
\text { Lepidochelys kempii }\end{array}$ & Brasil & & Marcolvaldi pers. com. \\
\hline
\end{tabular}


Caretta caretta, determinadas por su distribución geográfica: Caretta caretta en el Océano Atlántico y Caretta caretta gigas en el Océano Pacifico. Las diferencias entre las tortugas observadas en las dos áreas geográficas se basan en el número de placas marginales en el caparazón (7-12 y 7-8 respectivamente), aunque esta clasificación morfológica no es aceptada por algunos científicos, al parecer porque los ámbitos se sobrelapan (Lambert 1999). Estas diferencias entre localidades geográficas diferentes, también han sido descritas mediante estudios de genética molecular, en los cuales se ha demostrado pequeñas divergencias mediante análisis de DNA mitocondrial entre tortugas Caretta caretta del Atlántico y el Pacifico; la colonia de la cuenca del Atlántico presenta una baja diversidad de linaje de DNA mitocondrial, lo que estaría reflejando una reciente colonización de este océano por las tortugas Caretta caretta (Bowen 1996).

Sumado a la separación biogeográfica que permite el aislamiento genético, las presiones antrópicas que influyen en la reducción de poblaciones pueden estar ocasionado diferentes estrategias adaptativas para la especie Caretta caretta, como el intercambio genético con otras especies de la familia, que produce de esta forma individuos híbridos viables (Cuadro 3). $\mathrm{Si}$ las diferentes especies de tortugas marinas están utilizando la hibridación como una adaptación a cambios ambientales, es una pregunta que no se puede responder actualmente, lo que si se hace evidente es que desde años atrás se vienen registrando hibridación entre las diferentes especies de la familia Cheloniidae (Cuadro 3). La existencia de estos híbridos es extraordinaria porque las tribus Caretiini (Caretta caretta, Eretmochelys imbricata, Lepidochelys kempi) y Chelonini (Chelonia mydas y Natator depressus) (Bolten et al. 1993, Bowen 1996, Bowen et al. 2000) reflejan una división antigua entre la familia Cheloniidae, que data de por lo menos 50 millones de años (Avise et al. 1992). El incremento en la frecuencia de hibridación entre especies en vía de extinción, o entre estas y especies no amenazadas, puede marcar un acelerado decrecimiento y extinción de algunos taxa sensibles (Kamesaki 1990); sin embargo, es importante que sea considerado dentro de los planes de manejo y conservación esta parte de la historia de vida de las especies en estudio, ya que las predicciones acerca del impacto de la hibridación natural en poblaciones son difíciles de hacer (Bowen y Karl 1997).

Con el fin de dilucidar estos cuestionamientos, se deben realizar investigaciones encaminadas al análisis cariológico más fino, mediante el bandeo de cromosomas en localidades diferentes, que permitan determinar cambios entre áreas de anidación y alimentación. Además, teniendo en cuenta que en el ámbito espacial donde se han descrito híbridos se encuentra el Caribe colombiano y que en esta área no hay estudios genéticos de estas especies, se plantea la necesidad de identificar molecularmente individuos para aclarar si el cariotipo descrito en esta investigación se debe a la metodología utilizada, a separación biogeografica o a si son híbridos de Caretta caretta.

\section{AGRADECIMIENTOS}

Los autores agradecen al Acuario Mundo Marino, Santa Marta, Colombia, por proveer gentilmente las muestras de sangre de tortugas cabezonas, Caretta caretta.

\section{RESUMEN}

En los últimos años se ha registrado una disminución importante en el número de individuos de la tortuga marina Caretta caretta anidantes en el Caribe colombiano, situación que pone en evidencia la posibilidad de su extinción a mediano plazo. Por esto, es necesario implementar planes para su manejo y conservación. En este estudio se determinaron los requerimientos del cultivo de linfocitos de Caretta caretta para la obtención de cariotipos que permitan la identificación citogenética, el estudio inmunológico y toxicológico de individuos sin necesidad de sacrificarlos. Se muestrearon 47 individuos de C. caretta de Santa Marta, Colombia obteniendo sangre periférica con la que se realizaron ensayos de las diferentes variables hasta obtener las condiciones óptimas para el cultivo convencional de linfocitos. El cariotipo obtenido presentó 56 cromosomas: 32 macrocromosomas y 24 microcromosomas. El ideograma mostró que $C$. caretta tiene cuatro grupos de 
cromosomas: el grupo A compuesto por doce (12) pares de cromosomas de mayor tamaño. El Grupo B compuesto por cuatro (4) pares de cromosomas medianos y pequeños y el Grupo C conformado por 12 pares de microcromosomas. No se observaron cromosomas sexuales. Estos resultados están en desacuerdo con el cariotipo descrito por Kamesaki (1989), debido posiblemente a que las muestras analizadas en ese estudio fueron colectadas en el Océano Pacifico (Japón). El presente estudio es el primero realizado con tortugas del Océano Atlántico que cuenta con la descripción completa de la morfología cromosómica. Es posible, que una de las estrategias adaptativas de esta especie sea el intercambio genético con otras especies de la familia, que produce individuos híbridos viables. En este aspecto se ha descrito la hibridación de tortugas Caretta caretta con Eretmochelys imbricata, Chelonia mydas y Lepidochelys kempii, esto sugiere la posibilidad que los individuos caracterizados en este estudio sean híbridos viables de $C$. caretta, por lo tanto, se hace necesario realizar estudios a nivel molecular.

Palabras clave: cariotipo, cromosomas, ideograma Caretta caretta, Océano Atlántico

\section{REFERENCIAS}

Avise, J.C., B.W. Bowen, T. Lamb, A.B. Meylan, \& E. Bermingham. 1992. Mitochondrial DNA evolution at turtle's pace: evidence for low genetic variability and reduced microevolutionary rate in the testudines. Mol. Biol. Evol. 9: 457-473.

Bickham, J.W. 1975. A cytosystematic study of turtles in the genera Clemys, Mauremys and Sacalia. Herpetol. 31: 198-204.

Bickham, J.W. \& R.J. Baker. 1976. Karyotypes of some Neotropical turtles. Copeia. 4: 703-708.

Bickham, J.W., K.A. Bjorndal, M.W. Haiduk \& W.E. Rainey. 1980. The karyotype and chromosomal banding patterns of the green turtle (Chelonia mydas). Copeia 3: 540-543.

Bickham, J.W. 1981. Two Hunder Million old chromosomes: Declaration of the rate of karyotypic evolution in turtles. Sci. 212: 1291-1293.

Bickham, J.W. \& J.L. Carr. 1983. Taxonomy and phylogeny of the higher categories of Cryptodiran turtles based on a cladistic analysis of chromosomal data. Copeia 4: 918-932.
Bolten, A., E.R. Jacobson, \& K.A. Bjorndal. 1993. Effects of Anticoagulant and Autoanalyzer on Blood Biochemical Parameters of Loggerhead Sea Turtles, C. caretta. Amer. J. Vet. Res. 53: 2224-2227.

Bowen, B.W. 1996. Comparative biogeography of the green turtle (Chelonia mydas) and the loggerdhead turtle (C. caretta) as inferred from mtDNA sequence comparasions In B. W. Bowen y W. N. Witzell (Editores), Proceedings of the International Symposium on Sea Turtles Conservation Genetics, NOAA Technical memorandum NMFS-SEFSC-396:173.

Bowen, B.W. \& S.A. Karl. 1997. Population genetics, phylogeography and molecular evolution. In LUTZ, P.L., MUSICK, J.A. The Biology of Sea Turtle. CRC, Nueva York, EEUU.

Bowen, B., N.Fitzsimmons, \& C.Mortiz.2000. Identificación de poblaciones. In Eckert, K.L., K.A., Bjorndal, F.A., Abreu-Grobois, \& M. Donnelly, Técnicas de Investigación y Manejo para la Conservación de Tortugas Marinas. Grupo Especialista en Tortugas Marinas UICN/CSE. Publicación 4. UICN/CSE, Blanchard, Pensilvania, EEUU.

Clark M. S., W. J. Wall. 1986. Phylogenetic Implications of Karyotipic Variation in the Batagurinae (Testudines: Emydidae). Genetica. 70: 89-106.

Concençião, M.B., J.A. Levy, L.F Marins. \& M.A. Marcovaldi. 1990. Electrophoretic characterization of a hybrid between Eretmochelys imbricata and $C$. caretta (Cheloniidae). Comp. Biochem. and Physiol. Vol. 97B, No. 2: 275-278.

Darnell J., H. Lodish, D. Baltimore. 1988. Biología cellular y molecular. Labor, Barcelona, España.

Dutton, P. 1996. Methods for collection and preservation of simple for sea turtle genetic studies, p. 17-24. In B.W. Bowen y W.N. Witzell (Editores), Proceedings of the International Symposium on Sea Turtles Conservation Genetics, NOAA Techincal memorandum NMFS-SEFSC-396.173.

Hendrickson. J.R. 1980. The ecological strategies of sea turtles. Amer. Zool. 20: 597-608.

INVEMAR. 2000. Programa Nacional de Investigación en Biodiversidad Marina y Costera. PNIBM. Editado por Juan Manuel Díaz Merlano y Diana Isabel Gómez López. Santa Marta: Colombia. INVEMAR, FONADE, MMA. 
INVEMAR. 2002. Determinación de la distribución y del estado de conservación de las tortugas marinas en el Caribe colombiano. Informe Final. Convenio SECAB SECAB-INVEMAR, Santa Marta, Colombia.

Kamesaki, N. 1983. The possibility of hibridization between the loggerhead turtle, $C$. caretta and the hawksbill turtle, Eretmochelys imbricata, in specimens hatched from eggs collected in Chita Peninsula. Japan J. Herpetol. 10: 52-53.

Kamesaki, N. 1989. Karyotypes of the loggerhead turtle, $C$. caretta, from Japan. Zool. Sci. 6: 421-422.

Kamesaki, N.. 1990. Karyotype of the Haswkbill Turtle, Eretmochelys imbricata, from Japan, with notes on a method for preparation of Chromosomes from liver cells. Japanese J. of Herpetol. 13: 111-113.

Karl, S.A. 1996. Hybridization and taxonomy of marine turtles: anonymous nuclear DNA sequence analyses. In B.W. Bowen y W.N. Witzell (Editores), Proceedings of the International Symposium on Sea Turtles Conservation Genetics, NOAA Techincal memorandum NMFS-SEFSC-396.173.

Killebrew, F.C. 1975. Mitotic chromosomes of turtles: the pelomedusidae. J. Herpetol. 9:281-285.

Levan, A.K., A., Fredga, \& B., Sandberg. 1964. Nomenclature for centroméric position on chromosome. Hereditas 52: 201-220.

Lewis, C. 1940. The Cayman Islands and marine turtles. In The Herpetology of the cayman island. Bull. Japan Sci. Series 2: 156-155.

Maecha, S. 1998. Caracterización citogenética de Rhinoclemmys diademata (Mertens, 1954) (Testudina: Emididae). Universidad Nacional de Colombia, Facultad de Ciencias, Departamento de Biología. Trabajo de Grado. Bogotá, Colombia.
Marcovaldi, M.A., M.H. Godfrey \& N. Mrosovsky. 1997. Estimating sex ratios of loggerhead turtle in Brazil from pivotal incubation duration. Can. J. Zool. 75: 755-770.

Medrano, L.M., F. Dorizzi, C. Romblot, C. Pieau. 1987. Karyotype of the sea turtle Demochelys coriacea (Vandelli, 1761). Amphibia- Reptilia. 8: 171-178.

Nakamura, K. 1949. A study in some chelonians with notes on chromosomal formula in the Chelonia. Chromosome. 5: 205-213.

Ortiz, M. \& P. Rodríguez. 2003. Estudio citogenético de la tortuga "sabanera" (Podocnemis vogli. Müler, 1953) (Testudinata: Podocnemidae). Universidad Nacional de Colombia, Facultad de Ciencias, Departamento de Biología. Trabajo de Grado. Bogotá, Colombia.

Ortiz, M.L., P.A., Rodríguez, \& Bueno M.L. 2005. Caracterización citogenética de la tortuga sabanera Podocnemis vogli (Reptilia: Testudinata: Podocnemidae). Acta Biológica Colombiana Vol. 10 No 1.

PNCTMCC. 2002. Ministerio de Ambiente-Dirección General de Ecosistemas. Programa Nacional para la Conservación de las Tortugas Marinas y Continentales en Colombia. Bogotá, Colombia.

Ulsh, V.A., J.D. Congdon, T.G. Hinton, F.W. Whicker \& J.S. Bedford. 2001. Culture methods for turtles lymphocytes. Meth. in Cell. Sci. 22: 285-297.

\section{REFERENCIA DE INTERNET}

Lambert, J. 1999. C. caretta (On-line), Animal Diversity Web. http://animaldiversity.ummz.umich.edu/ site/accounts/information/Caretta caretta.html. Consultado 2 mayo 2008. 
